\title{
O jogo é a excalibur para o ensino de ciências? apontamentos para pensar o lúdico no ensino de conceitos e na formação do professor
}

Hélio da Silva Messeder Neto messeder3@gmail.com orcid.org/0000-0002-6620-2989 Universidade Federal da Bahia (UFBA), Salvador, Bahia, Brasil

\section{RESUMO}

Em linhas gerais, a lenda do Rei Artur conta a história de um garoto predestinado que teria se tornado rei ao retirar de uma pedra a famosa espada mágica, chamada Excalibur. Usando essa história como metáfora, este artigo traz como objetivo problematizar concepções inatistas e apolíticas do lúdico para a formação dos professores. Assim como, a ideia da ludicidade como uma forma mágica de resolver todos os problemas da escola; além de trazer apontamentos para o uso do lúdico como forma de ensinar conceitos científicos. Tomando a psicologia histórico-cultural como referência, o artigo, de cunho teórico, apontou como um de seus resultados a ideia de que, para que o lúdico contribua para a aprendizagem de conceitos científicos, ele deve pôr o estudante em atividade, para que o mesmo mobilize seus processos psicológicos. Para que tais fatores ocorram, a atividade precisa ser pensada de modo que os conceitos ocupem lugar de destaque durante o jogo. Outro resultado do artigo aponta para uma formação ludo-política por parte do professor de Ciências, a fim de que os jogos e outras atividades lúdicas sejam utilizadas de maneira consciente para que tragam consigo uma visão de mundo mais crítica da realidade, e não apenas uma visão reprodutora de preconceitos. Por fim, é defendida a importância de caminhar para um uso mais consciente e sistemático do lúdico no ensino de Ciências.

PALAVRAS-CHAVE: Ludicidade. Formação do professor. Ensino de conceitos. Ensino de Ciências. 


\section{INTRODUÇÃO: O LÚDICO E A LENDA DO REI ARTUR}

Em linhas gerais, a lenda do Rei Artur conta a história de um garoto de 15 anos que, ao se tornar rei, consegue reunir tropas contra os bárbaros saxões que tentavam invadir o então território da Bretanha. Sob a égide de Artur, o reino de Camelot viveu em paz durante 50 anos, reunindo seus melhores cavaleiros em uma távola redonda - que tinha como simbolismo central a ideia de que todos eram iguais perante o governante. Artur teria se tornado rei ao retirar de uma pedra a famosa espada mágica, chamada Excalibur. A espada só poderia ser retirada pelo escolhido, e, apesar de bravos e fortes guerreiros, oriundos de várias partes da região, terem tentado, apenas Artur conseguiu bradar a arma e se tornar o rei poderoso e unificador de povos que estava destinado a ser.

Essa lenda, narrada e adaptada diversas vezes, tanto no cinema quanto na literatura, destaca que para se tornar um grande líder e guerreiro duas características seriam essenciais: ser predestinado a isso e ter um instrumento mágico capaz de ajudá-lo a conduzir o povo à liberdade.

Se tomarmos a história do rei Artur como metáfora, e fizermos uma análise da produção do lúdico no Brasil, poderemos ver que muitos trabalhos ainda entendem que as atividades lúdicas são a Excalibur para o ensino de Ciências: uma arma mágica capaz de resolver todos os problemas da sala de aula.

Essa ideia reforça aquilo que já tínhamos definido em outro trabalho, quando afirmamos que:

\footnotetext{
Para muitos, o lúdico ganhou esse status de panaceia para resolver os problemas da escola. As quantidades de jogos da memória, ou supertrunfos para ensinar tabela periódica se avolumam na sala de aula, na esperança de que os alunos olhem para o professor, por alguns segundos e, finalmente, entendam o que é um elemento químico ou o que representa aquele $\mathrm{OH}$ na estrutura de uma molécula de etanol (MESSEDER NETO, 2016, p. 27).
}

A ideia de que só alguns poderiam usar essa ferramenta dotada de poderes e, portanto, seriam predestinados, também paira no imaginário dos professores. 0 lúdico seria algo intrínseco, logo, alguns professores seriam lúdicos e poderiam usar jogos na sala de aula, enquanto outros não. Sendo assim, a ludicidade seria algo que só poderia ser usada por alguns, restrita, portanto, a professores "escolhidos". Tais noções apontam para um esvaziamento político-metodológico da formação lúdica do professor, uma vez que usar a ludicidade seria algo intuitivo.

No intuito de problematizar concepções inatistas e apolíticas do lúdico para formação dos professores e a ideia da ludicidade como uma forma mágica de resolver todos os problemas da escola, escrevemos esse artigo. A partir da psicologia histórico-cultural, esse texto tentará apontar algumas armadilhas e potencialidades do lúdico no processo de ensino de conceitos científicos, e destacará elementos para pensar a formação lúdica do professor no ensino de Ciências. 


\section{QUE ESPADA É ESSA PRESA NA ROCHA? ELEMENTOS DO LÚDICO PARA PENSAR A APRENDIZAGEM DE CONCEITOS CIENTÍFICOS}

O ensino de conceitos é sempre um grande desafio para o trabalho docente. Isso porque a incorporação de conceitos científicos, segundo Vigotski (2009), é um processo longo que não se dá, simplesmente, com o conhecimento da palavra, ou a memorização de uma definição. Em realidade, ocorre com a apropriação dos vínculos e relações sobre o objeto de estudo em seu movimento histórico, o que exige a mobilização de funções do psiquismo.

Este processo de desenvolvimento dos conceitos ou significados das palavras requer o desenvolvimento de toda uma série de funções como a atenção arbitrária, a memória lógica, abstração, a comparação e a discriminação, e todos esses processos psicológicos sumamente complexos não podem ser simplesmente memorizados, simplesmente assimilados (VIGOTSKI, 2009, p. 246).

O processo de desenvolvimento conceitual, portanto, está longe de ser simples e exigirá do professor um conjunto de atividades que ponham essas funções em movimento, as quais permitirão que o sujeito desenvolva esses processos psíquicos.

Aqui está um elemento importante para a obra vigotskiana. A instrução que permite a aprendizagem de conceitos precede o desenvolvimento dessas funções psíquicas, ou seja, Vigotski não propõe uma pedagogia da espera, onde o professor aguarda o estudante amadurecer o pensamento abstrato para ensinar abstração, ou espera o aluno ter pensamento lógico para o desenvolvimento da lógica. Tratase do contrário. As funções psicológicas se desenvolvem na medida em que delas são exigidas funcionamento. Desse modo, é o ensino da Matemática que desenvolve o pensamento matemático, é o ensino de conceitos científicos que desenvolve a abstração, a atenção voluntária. Podemos dizer, por conseguinte, que a aprendizagem de conceitos científicos exige o uso das funções psicologias complexas e, ao requerer esse uso, promove desenvolvimento.

Eis o motivo de podermos afirmar que nem todo ensino é um ensino desenvolvimentista. O ensino que promove o desenvolvimento é justamente aquele que vai exigir do estudante mobilizar processos funcionais psíquicos que não estão prontos, mas que estejam na iminência de se desenvolver e, além disso, permite que o mesmo vá além dos cárceres imediatos daquilo que acabou de aprender.

\footnotetext{
Se aprendermos datilografia, na estrutura da nossa consciência pode não haver nenhuma mudança. Mas se aprendermos, digamos, um novo método de pensamento, um novo tipo de estrutura, isso nos dá a possibilidade não só de desenvolver a mesma atividade que fora objeto da atividade imediata mas nos dá muito mais: dá a possibilidade de ir além dos limites daqueles resultados imediatos a que a aprendizagem conduziu (VIGOTSKI, 2009, p. 303).
}

Ao assumir, em vista disso, que uma rica aprendizagem pode promover o desenvolvimento psíquico do sujeito, Vigotski está destacando três pontos importantes que o professor de Ciências precisa considerar. O primeiro deles, já sinalizado, mas que precisa ser destacado, é que a aprendizagem de conceitos vai além de si mesma. Assim sendo, ao aprender, de fato, os conceitos científicos, seus 
pensamentos, sua forma de ver o mundo e seus sentimentos mudam, indo para além daquilo que aprendeu. Quando o sujeito aprende conceitualmente a Química, a Física e a Biologia, por exemplo, o modo como ele age, pensa e sente o mundo também muda; uma vez que, esses conhecimentos, retroagem sobre o psiquismo do sujeito, fazendo-o ir além - como nos disse Vigotski, na citação acima - dos resultados imediatos que aprendeu.

Antes de passarmos para o segundo ponto, precisamos fazer um destaque. Quando defendemos aqui que a aprendizagem de conceitos retroage sobre o psiquismo do sujeito não estamos querendo dizer com isso que o desenvolvimento acontece junto com o ensino de cada conceito, ou seja, o professor não deve esperar revoluções psíquicas no sujeito quando ele aprende o conceito de calor, de evolução ou sobre átomo. Isto porque, como nos diz Vigotski, apesar da aprendizagem desses conceitos contribuírem para o desenvolvimento psíquico, este não está subordinado ao programa escolar. Nas palavras do próprio Vigotski:

O desenvolvimento não se subordina ao programa escolar, tem sua própria
lógica. Até hoje ninguém demonstrou que cada aula de aritmética pode
corresponder a cada passo no desenvolvimento, digamos, da atenção
arbitrária, embora, em linhas gerais, a aprendizagem da aritmética exerça
indiscutivelmente uma influência substancial sobre a passagem da atenção
do campo das funções psíquicas inferiores para o das funções superiores
(2009, p. 324).

O segundo ponto de destaque é que, se a aprendizagem precede o desenvolvimento e o promove, a escola não pode olhar simplesmente para aquilo que a criança sabe e deixá-la presa em suas concepções prévias, ou ficar repetindo que ela não aprendeu o conteúdo da série anterior. É preciso que o ensino esteja voltado para aquilo que o sujeito ainda não sabe, naquilo que ele pode aprender. É preciso mudar o olhar voltado apenas em carências e ausências, e focá-lo também nas potências e possibilidades. Trata-se de tentar trazer uma aprendizagem desafiante, que não esquece o que a criança já sabe, mas que olha para o futuro:

\begin{abstract}
Antes se perguntava será que a criança já amadureceu para aprender a ler e contar? A questão das funções amadurecidas permanece em vigor. Cabe definir sempre o limiar inferior da aprendizagem. Mas a questão não termina aí, e devemos ter a capacidade para definir também o limiar superior da aprendizagem. Só na fronteira entre esses dois limiares a aprendizagem pode ser fecunda. Só entre elas se situa o período de excelência do ensino de uma determinada matéria. A pedagogia deve orientar-se não no ontem, mas no amanhã do desenvolvimento da criança (VIGOTSKI, 2009, p. 333)
\end{abstract}

A partir desses dois pontos podemos derivar o terceiro. Se aprendizagem precede o desenvolvimento e a escola precisa olhar para o futuro, assim, um sujeito que sabe mais do que outro e que pode ajudar o indivíduo a avançar é crucial para o desenvolvimento psíquico. Portanto, no bojo dessas discussões é que Vigotski evoca o conceito de Zona de Desenvolvimento Iminente (ZDI) ${ }^{1}$. Para o autor, aquilo que a criança não faz sozinha, mas, em colaboração com o par mais capaz, é o que está incluso na ZDI. Quando Vigotski defende uma escola que olhe o amanhã e que projete o desenvolvimento, ele está justamente defendendo um ensino que atue na ZDI, dessa forma, propondo que, o que hoje ele faz acompanhado e com ajuda, amanhã fará sozinho. 
Esse conceito tem sido muito utilizado na área de Ensino de Ciências quando as crianças são colocadas para trabalhar em grupo. Entende-se que as crianças que sabem mais teriam capacidade de ajudar o colega que não sabe tanto. A ajuda de outros colegas é realmente relevante no processo educativo, contudo, precisamos destacar que atuar na ZDI, e ajudar a criança a projetar o desenvolvimento psíquico diante da aprendizagem de conceitos, não deve ser responsabilidade de nenhuma outra criança, por mais que ela tenha um conhecimento a mais que o colega. Isso significa que, na escola, o par mais capaz, por excelência, responsável por fazer os sujeitos desenvolverem a rede conceitual necessária para potencializar suas funções psicológicas e achar estratégias para isso, é o professor. Encontramos reforço para essa afirmação nos escritos de Martins (2013, p. 288):

\begin{abstract}
Porém, não há dúvida de que o autor [Vigotski] destacou o papel da colaboração externa e, igualmente, os benefícios da influência do par mais desenvolvido, mais experiente. A objeção em pauta refere-se ao risco de se tomar com igual importância a participação do "par professor" e de outros pares, diluindo o papel do primeiro na condução da aprendizagem Ora, se atuar na "área de desenvolvimento iminente" [ZDI] pressupõe o trato com pendências interfuncionais, com pendências afetivo-cognitivas, há que se identificá-las e planejadamente agir sobre elas. Essa não nos parece ser tarefa de nenhuma outra criança, por mais experiente que seja.
\end{abstract}

Eis a justificativa para que o processo de formação do professor tenha uma base conceitual sólida para que este possa, de fato, atuar como par mais capaz, auxiliando o estudante a atingir outros patamares que, de outro modo, não seriam alcançados sozinhos ou através de consultas espontâneas na internet.

Cabe aqui apontar outro destaque sobre a ZDI. Quando falamos que o estudante será capaz de fazer sozinho o que hoje ele faz em colaboração com o par mais capaz, não estamos reduzindo isso ao processo de resolução de uma prova. Saber resolver sozinho uma atividade, ou uma prova, não significa que aquele conceito se efetivou como sendo, de fato, pertencente ao psiquismo do sujeito.

Isso porque, pela natureza dos conceitos científicos, o sujeito precisa trazer para o nível da consciência um conjunto de complexas relações do objeto em estudo, de modo a captá-lo na essência daquilo que o caracteriza e o vincula com os outros conceitos. Para que isso se efetive são necessários diversos mergulhos e aproximações com o que se está estudando, de diferentes modos e em diferentes situações, evidenciando sempre aquilo que o estudante não aprendeu de imediato e que não está visível simplesmente pela manipulação do objeto.

Em vista disso, o processo de resolução de uma prova ou de uma atividade feita no processo de aprendizagem tende a revelar a apropriação inicial do conceito científico, mas não ainda uma conquista efetiva, que, caso não continue sendo trabalhada, será esquecida pelo estudante. Nós, professores, comumente tomamos o emprego dos termos científicos em uma ou duas situações, de fato, um desenvolvimento conceitual. Contudo, ali está o início do processo e não o seu final. Vejamos o que nos diz Vigotski: 
ela é sempre uma palavra imatura. O gradual desenvolvimento interno do seu significado redunda também no amadurecimento da própria palavra. Aqui, como em toda parte, o desenvolvimento do aspecto semântico é o processo básico e decisivo do desenvolvimento do pensamento e da linguagem da criança. Como diz Tolstói, a palavra quase sempre está pronta quando o conceito está pronto; isso quando se costumava supor que o conceito estivesse sempre pronto quando a palavra estava pronta (VIGOTSKI, 2009, p. 394 , grifo nosso).

Entendemos, portanto, que os conceitos científicos se efetivarão como tal quando forem usados de maneira consciente pelo indivíduo, interpondo-se como signo na consciência que (trans)forma o psiquismo do sujeito, pertencendo agora ao seu sistema conceitual. De tal modo que passa a ocupar o status de ferramenta psíquica de segunda natureza (natureza social), podendo ser evocada quando o sujeito voluntariamente se coloca diante de uma situação de decodificação do real.

A partir desta mesma perspectiva, Saviani defenderá, a partir do exemplo da alfabetização, a necessidade de formação de um habitus para se falar de uma real conquista no campo da aprendizagem de algum conceito:

[...] só se aprende, de fato, quando se adquire um habitus, isto é, um uma disposição permanente, ou, dito de outra forma, quando o objeto de aprendizagem se converte numa espécie de segunda natureza. $E$ isso exige tempo e esforços por vezes ingentes. A expressão segunda natureza pareceme sugestiva justamente por que nós, que sabemos ler e escrever, tendemos a considerar esses atos como naturais. Nós os praticamos com tamanha naturalidade que sequer conseguimos nos imaginar desprovidos dessas características. Temos mesmo dificuldade em nos recordar do período em que éramos analfabetos. As coisas acontecem como se se tratasse de uma habilidade natural e mecânica. As coisas acontecem como se tratasse de uma habilidade natural e espontânea. E, no entanto, trata-se de uma habilidade adquirida e frise-se, não de modo espontâneo (SAVIANI, 2008, p. 20).

Diante do exposto, qualquer atividade lúdica na sala de aula precisa estar a serviço do ensino de conceitos que promova desenvolvimento ${ }^{2}$. Afinal, de nada adiantará uma atividade divertida na sala de aula se ela não ajudar a escola, nesse caso, no cumprimento da sua função de disponibilizar para os sujeitos conceitos científicos acumulados pela história da humanidade. Ou seja, o lúdico precisa ser uma forma de ajudar o professor a mobilizar os processos psíquicos dos estudantes para que, assim, eles aprendam os conceitos que incidirão sobre seu desenvolvimento.

Para que os jogos e outras atividades lúdicas cumpram essa função, o professor precisa ficar atento, uma vez que os conceitos presentes precisam mobilizar o estudante exigindo dele mais do que ele é capaz de fazer sozinho. 0 jogo precisa ser desafiador para o estudante, não só do ponto de vista lúdico (uma fase difícil, um jogo de regras elaboradas), mas do ponto de vista educativo daquilo que a atividade se propõe a ensinar/revisar/avaliar.

Um exemplo pode ajudar o leitor a entender o que aqui defendemos. É muito comum na literatura o uso do jogo da memória de química orgânica, no qual os alunos devem associar o nome da função orgânica com a estrutura do grupo funcional (no jogo, $\mathrm{C}-\mathrm{OH}$ estaria em uma carta, e esta deveria ser associada à função álcool, por exemplo). Esse tipo de jogo exige muito pouco do campo conceitual do aluno. Entender a função orgânica como conceito é muito mais do 
que reconhecê-la na estrutura de uma molécula, é entender que aquele grupo modifica as propriedades físicas, a reatividade das substâncias e seus usos pela humanidade.

Por mais que esse jogo seja aparentemente "motivador", engaje o estudante e faça a relação entre professor e aluno melhorar, isso não será suficiente se servir apenas para mobilizar estruturas que o aluno já tem. Em verdade, essa atividade deve projetar o estudante a mobilizar estruturas conceituais complexas que não se efetivarão simplesmente na associação do grupo funcional com a estrutura orgânica, como no exemplo apresentado. É preciso que a intervenção lúdica aponte para criar no indivíduo novas necessidades. Como nos diz Saccomani (2016, p. 180):

\begin{abstract}
O ensino que promove desenvolvimento traz à atividade do sujeito experiências humanas que o farão ir além do que tem sido sua atividade até o momento, expandindo-a e produzindo novas necessidades. Pode-se fazer um paralelo com o que Marx chamou de primeiro ato histórico, isto é, a produção dos meios de satisfação das necessidades, que, por sua vez também produz novas necessidades. O ensino, ao mesmo tempo em que transmite o conhecimento acumulado, também faz a atividade do sujeito ir além, produzindo novas necessidades. Assim, o sujeito consegue realizar coisas que sozinho não conseguiria.
\end{abstract}

Isso significa que jogos de memória ou outros jogos de tabuleiro simples e adaptados não possam ser utilizados? Sim, podem - desde que o professor não coloque essas atividades com um fim em si mesmas. Do ponto de vista da mobilização de conceitos, essas atividades são simples e empobrecidas e, portanto, precisam ser complementadas, discutidas e ampliadas, de modo a utilizar outros recursos que permitam enriquecer a teia conceitual do estudante.

Jogos mais elaborados, que permitam ampliar e gerar uma mobilização mais aperfeiçoada de conceitos, precisam ser mais bem pensados pela comunidade. $O$ estágio de divertimento e interesse despertado pelo jogo precisa ser aproveitado como gatilho, a fim de oferecer aos estudantes conexões mais elaboradas dos conteúdos estudados em seu movimento histórico. Aqui, portanto, deve ficar evidente que trata-se de uma armadilha pensar como simples ou intuitivo elaborar/aplicar um jogo educativo que trabalhe com conceitos científicos. A elaboração de uma atividade lúdica requer planejamento, clareza teóricometodológica e também conceitual daquilo que se quer ensinar, de modo a garantir que o jogo não mobilize apenas o conteúdo no aspecto verbalista do conceito, mas o faça no aspecto semântico, penetrando na estrutura do que se quer ensinar.

\footnotetext{
O professor, ao assim proceder, não se torna um mero arquiteto de aulas supostamente "dinâmicas" nem um coadjuvante de aprendizagens individualizadas e subjugadas às ações empíricas dos alunos, mas aquele que faz avançar e resolve as pendências cognitivas engendradas por tais ações. Portanto, sem uma sólida formação teórico-conceitual e didáticometodológica, por mais interessantes que estes procedimentos sejam, não resultarão férteis na promoção da aprendizagem (MARTINS, 2016, p. 18).
}

O papel do colega no jogo é outra armadilha que o educador costuma trazer de maneira espontânea. Assumir que naturalmente o jogo é uma atividade colaborativa que atua na ZDI e que, portanto, os estudantes se ajudam e o par mais 
capaz orienta o sujeito que está aprendendo pode não ser verdade a depender do processo de condução da atividade e da sua concepção. Nos jogos os estudantes entendem que precisam atingir um objetivo e aqueles que não aprenderam o conteúdo impedindo que o grupo chegue ao final desejado costumam ser deixados de lado ou esquecidos no jogo didático. Isso não acontece necessariamente por que os estudantes não querem se ajudar. $O$ jogo acontece em um determinado tempo onde as rodadas são relativamente curtas e isso dificulta com que o estudante que sabe mais faça uma intervenção que possa ajudar o estudante que ainda está aprendendo, uma vez que se ele parar para explicar o objetivo do jogo não será alcançado.

O professor precisa, portanto, ao elaborar atividades lúdicas, pensar em regras que permitam que os estudantes interajam entre si e que auxílios e dicas possam ser dados aos estudantes que dominam menos aquele conteúdo durante o jogo, para que assim tenhamos uma ajuda do par mais capaz durante o processo.

Entretanto, cabe destacar que, como vimos ainda neste artigo, nenhum par mais capaz substitui o professor nesse processo, principalmente na atividade lúdica. Desse modo, no momento que o jogo está acontecendo o professor precisa ficar extremamente atento. Ele precisa anotar o que os estudantes estão tendo dificuldades, na medida do possível ouvir o que os grupos estão discutindo (se o jogo foi feito em grupo), ver os alunos que não estão participando e pensar em outras estratégias para mobilizar o conhecimento desses estudantes. Enfim, ao aplicar o jogo em sala de aula, em hipótese alguma, o professor pode entender que este é um momento livre para ele, onde não terá um papel pedagógico. Ao contrário, durante a situação lúdica, o professor precisa estar completamente presente, atento às pendências e aos pequenos avanços realizados pelos alunos durante o processo.

Temos defendido, também, que é trabalho do professor fazer as sínteses dos aspectos essenciais trabalhados durante o jogo, pois, na atividade lúdica, é essencial que o professor retome o que foi discutido, evitando que o conteúdo tenha ficado disperso na empolgação lúdica ou passado despercebido por algum estudante. Eis porque advogamos que:

\footnotetext{
A possibilidade de fazer síntese ao final do processo permite organizar uma série de informações que aparecem fragmentadas durante as discussões. Essa síntese permite que alguns estudantes reconsiderem o que falaram e o que deixaram de falar durante as respostas. Sem isso a atividade corre o risco de se perder em informações soltas e mantermos os estudantes em uma síncrese e não levando a eles um pensamento sintético (MESSEDER NETO 2016, p. 201).
}

Como podemos perceber aqui, o uso de atividades lúdicas na sala de aula está longe de ser uma atividade trivial que pode ser elaborada em poucos minutos e então aplicada. Ela requer estudo e consciência pedagógica para que suas potencialidades sejam aproveitadas. O lúdico precisa ser pensado como um modo de cortar caminho, de modo que o estudante se aproprie do conhecimento científico sem, no entanto, ficar refém dessa forma.

O jogo ou qualquer outra atividade lúdica é, portanto, ponto de partida e não ponto de chegada do processo educativo (MESSEDER NETO, 2016). Quando afirmamos isso, não estamos asseverando que o jogo só pode ser usado no começo 
de uma intervenção didática, mas que, em hipótese alguma, o jogo se encerra nele mesmo. Será sempre necessário e desejável que o professor cuide para que os aspectos essenciais do conteúdo sejam retomados, mesmo que o jogo seja usado como avaliação.

O lúdico no ensino de química é ponto de partida e não de chegada. Se isso não acontece o professor torna-se refém das atividades lúdicas e não é legítimo que o interesse pela química apareça apenas quando o aluno joga. É possível e interessante que os professores usem jogos, mas é condição sinequa non que ao final do processo pedagógico o professor possa prescindir deles (MESSEDER NETO, 2016, p. 226, grifo no original)

Além da relação com o conteúdo, outros aspectos precisam ser levados em consideração quando falamos da ludicidade no processo de formação de professores. Sem perder de vista o que até aqui foi discutido, e a importância do conhecimento científico para um ensino desenvolvimentista, passemos para o próximo tópico deste texto.

\section{QUEM É O REI QUE VAI TIRAR A ESPADA? O PAPEL POLÍTICO DO LÚDICO NO PROCESSO FORMATIVO DO PROFESSOR}

A ideia de que a ludicidade nasce com o professor ou nasce com o sujeito também precisa ser combatida no campo do processo formativo do educador. $O$ professor que usa o lúdico no ensino não precisa, necessariamente, ser um piadista ou entrar na sala de aula fantasiado. O lúdico precisa ser pensado como uma forma específica que visa viabilizar o conteúdo para o estudante, e seja utilizada de modo que o professor conheça os limites e possibilidades de tal atividade.

Isso significa que o educador, ao levar jogos e outras atividades divertidas para sala de aula, não deve ser visto como alguém predestinado ou que tenha um dom, mas como um profissional que pensa nesse recurso para garantir a aprendizagem. Eis que o professor precisa no seu processo formativo desenvolver a intencionalidade lúdica. Para Felício e Soares $(2018$, p. 7), a intencionalidade lúdica é definida como:

\footnotetext{
[...] a atitude consciente do professor voltada e orientada ao equilíbrio do aspecto prazeroso e pedagógico da atividade lúdica a ser desenvolvida. Tal aspecto se faz imensamente importante e deve ser o orientador de qualquer atividade proposta em sala de aula, ou em qualquer outro ambiente, pertinente a atividade do fazer docente. O professor que queira se utilizar do lúdico em sala de aula, deve querer de fato fazê-lo. Sem intencionalidade real, o jogo proposto ou a postura proposta tendem a falhar.
}

A discussão do lúdico, no processo de formação de professores, não pode prescindir de uma discussão política do papel da escola, de visão de mundo, de sujeito e de conhecimento científico.

É importante que o professor tenha clareza da importância da forma lúdica para o ensino. Contudo, essa forma só ganhará corpo quando estiver alinhada com os objetivos gerais mais amplos, vinculados ao trabalho do professor. Em uma sociedade dividida em classes, por exemplo, será importante que o professor posicione claramente de que lado ele está, e a que tipo de sociedade o conhecimento que ele ensina favorece. Quando efetivamente, e de maneira 
consciente, a visão de mundo do professor reflete nos procedimentos lúdicos de ensino, é que podemos dizer que estamos diante de uma atividade lúdica realmente pedagógica.

Sem debater e tensionar, de maneira explícita, concepções sobre as visões de mundo que perpassam a elaboração e aplicação das atividades lúdicas dentro da sala de aula, os professores podem usá-las para reforçar estereótipos, preconceitos e ideologias, os quais prejudicarão, principalmente, os filhos pobres da classe trabalhadora e da escola pública.

É comum, por exemplo, aparecer refletido no senso comum uma ideia burguesa que suspeita da capacidade intelectual da população pobre, pensando nesses sujeitos como marginais ou incompetentes, e com uma família abstrata desestruturada. Tais ideias são, comumente, utilizadas para explicar o fracasso escolar (repetência, evasão e dificuldades de aprendizagem) da população carente e, assim, obnubilar questões gerais históricas, políticas e econômicas que perpassam o processo educativo. O olhar de muitas formações de professores sobre os alunos pobres ainda é um olhar de suspeita, calcado no Brasil em um racismo estrutural.

Basta reconhecer que, ainda hoje, impera no Brasil um olhar conduzido para os pobres, colocando-os, na melhor das hipóteses, no lugar de suspeitos. E suspeitamos! Ora de sua capacidade cognitiva, ora de sua conduta moral. E de suspeitos, os pobres passam a engrossar tristes estatísticas: do sistema carcerário, de desemprego ou subemprego; do fracasso escolar. São os pobres os mais atingidos por "balas perdidas". Balas que a jornalista Eliane Brum melhor nominou como "achadas", já que encontram corpos sempre nos mesmos bairros, geralmente aqueles nos quais o único aparelho estatal que entra, e sem pedir licença, é a polícia (VIÉGAS, OLIVEIRA; MESSEDER NETO, 2017, p. 79³).

Se o professor de Química assume essa ideia, sem problematizá-la, será muito fácil que ele leve para sala de aula jogos fáceis e bobos que tragam conhecimentos rarefeitos e pouco aprofundados - uma vez que ele entenderá que os alunos são incompetentes e fracassados, incapazes de aprender. Se imbuído da ideia, ainda que tácita, de que o pobre precisa aprender pouco, já que não há muito que fazer, a ludicidade ganha contornos de passatempo, algo que esvazia as escolas e nega aos estudantes da classe trabalhadora o domínio de conteúdos científicos. E, como bem nos diz Saviani, sem tais conhecimentos, o processo de ensino se converte em farsa:

\footnotetext{
Os conteúdos são fundamentais e sem conteúdos relevantes, conteúdos significativos, a aprendizagem deixa de existir, ela transforma-se num arremedo, ela transforma-se numa farsa (...). Eu costumo, às vezes, anunciar isso da seguinte forma: o dominado não se liberta se ele não vier a dominar aquilo que os dominantes dominam. Então, dominar o que os dominantes dominam é condição de libertação (SAVIANI, 2008, p. 45).
}

Outro aspecto político a ser problematizado é a questão do divertimento inerente à atividade lúdica. Os alunos se divertem a partir de que? Do que os alunos estão rindo ${ }^{4}$

A discussão política do riso já aparece em alguns trabalhos (GOMES, 2013), prática do professor, quando usa piadas ou quando constrói analogias de tom 
humilhante, ou no uso de jogos e filmes com situações cômicas, o riso não pode ser desvinculado da perspectiva que o mesmo carrega. Isso significa que, mesmo que o professor não esteja, propositalmente, querendo transmitir valores quando faz uma "inocente" piada ou leva um "simples" jogo para sala de aula, ele o faz. Podemos encontrar reforço em Gomes, quando a mesma traz a discussão sobre obras estéticas:

Entender que todas as obras estéticas possuem um sentido político não acarreta no engajamento das mesmas, mas, sim, compreender que no discurso estético existem as marcas de seu contexto e que estas possuem algum posicionamento, seja por meio do incentivo à determinado estilo de vida ou através do merchandising de algum produto (GOMES, 2013 p. 15).

O riso e o divertimento precisam ser objeto de análise, pois atividades lúdicas pensadas de maneira inocente pelo professor podem gerar práticas em sala de aula que reforcem estereótipos de gênero, preconceitos de diversas ordens, segregue grupos e/ou humilhe os estudantes. Os sentimentos despertados nas atividades lúdicas precisam passar a ser alvo, também, do pensamento pedagógico do professor, que precisa entender que tais sentimentos despertados na atividade podem ser cruciais na aprendizagem do sujeito. Assim como, os vínculos que serão estabelecidos com a Química, uma vez que, para a psicologia histórico-cultural, não há sentimento apartado do pensamento.

Se no jogo, o aluno assume uma atitude racista ou machista, por exemplo, o professor de Química precisa saber se posicionar e precisa pensar como fará isso. Mas, para que ele saiba lidar com essas situações, tais elementos políticos precisam estar presentes na sua formação de professor, e, também, precisam ser abordados relacionados com sua prática pedagógica.

É claro que situações de preconceito podem aparecer em outras atividades, mas como nas atividades lúdicas se constitui um ambiente descontraído, há muita chance desses elementos preconceituosos se revelarem por meio do riso e da brincadeira. Pensamos, portanto, que fica nítido que o lúdico precisa aparecer na formação do professor não como simples técnica, mas como forma de ensino que faz efervescer seu aspecto político e intencional na consciência pedagógica do professor.

Fazemos uso do termo "forma" em consonância com Martins (2013) e Duarte (2016), entendendo que, tal termo, traz consigo a dialética com o conteúdo sendo, portanto, impossível pensar que exista um modo de ensinar desprovido de intencionalidade e visão de mundo. Assumir o lúdico como forma de ensino carrega, para nós, a ideia clara de que as concepções subterrâneas que aparecem quando se usam jogos na sala de aula precisam ser trazidas à tona, não naturalizadas, tendo que ser refletidas continuamente pelos professores em formação inicial e continuada.

\section{CONSIDERAÇÕES FINAIS: DESTRONANDO O REI E DESTRUINDO AS ESPADAS}

O uso de qualquer forma de ensinar requer responsabilidade e intencionalidade pedagógica. Para que as formas não sejam usadas de maneira aleatória, o professor deve conhecer as limitações e potencialidades de cada 
recurso, pensando como eles se adequam ao conteúdo a ser ensinado e ao destinatário para qual a atividade pedagógica foi planejada.

No campo do lúdico no Ensino de Ciências isso não é diferente. Ao propor um jogo educativo, uma música ou um filme, o professor precisa estar consciente da força que uma atividade lúdica tem para envolver o estudante numa situação que permita a apropriação de um conceito científico, assim como os entraves que poderá encontrar na execução e planejamento da atividade. É preciso que o professor reconheça a cientificidade do lúdico e destrone a ideia de que esse se trata de um recurso mágico resolvedor de todos os problemas da escola. É preciso quebrar essa ideia de que a ludicidade é a Excalibur e avançar, no sentido de pensar o lúdico como apenas mais um recurso do campo do ensino de Ciências, o qual pode ser usado pelo professor quando este achar que o ensino de conceitos será favorecido via essa forma. O lúdico só terá sentido pedagógico real se ajudar o estudante na apropriação do conhecimento científico, caso contrário, se configurará em uma armadilha perigosa para a sala de aula.

Se a concepção da ludicidade como a Excalibur precisa ser banida, a ideia de um rei predestinado ao uso do lúdico também precisa ser superada. Não há um rei, ou professor, predestinado para usar uma atividade lúdica na sala de aula. $\mathrm{O}$ lúdico precisa ser objeto de formação do educador em Ciências. Fugindo ao espontaneísmo, o professor precisa ser formado para usar jogos em sala de aula que, de fato, favoreçam a aprendizagem.

Defender uma formação lúdica na formação dos professores é mais do que advogar por uma disciplina que apresente um punhado de jogos de tabuleiros e aplicativos para usar nas aulas de cinética ou química orgânica, por exemplo. É preciso uma formação ludo-política, na qual a concepção de mundo aparece como objeto de atenção e ajude o educador a pensar, inclusive, quais atitudes humanas aqueles jogos reforçam; que elementos estão presentes no jogo e são motivos de gracejos e diversão; qual concepção de sociedade está naquele jogo aplicado na aula.

Superar o espontaneísmo do lúdico, essa noção de que se trata de algo fácil ou sem importância e que pode ser aplicado de qualquer modo, ainda é um desafio que enfrentaremos durante um tempo no campo do Ensino de Ciências. Esperamos que este artigo tenha trazido subsídios para ampliar o olhar sobre a ludicidade. Bem como, auxilie na caminhada contrária do uso intuitivo, pouco refletido, mágico ou de solução fácil para resolver problemas complexos da educação, do ensino e da aprendizagem.

Na ausência de reis predestinados ou espadas mágicas tiradas das pedras, temos que nos articular como educadores para garantir que a escola cumpra sua função precípua de ensinar os estudantes sobre a realidade, para que, de posse desse conhecimento, ela possa ser transformada. 


\title{
Is the game the excalibur for science teaching? notes to think the playful in teaching concepts and in teacher training
}

\begin{abstract}
Generally speaking, the legend of King Arthur tells the story of a predestined boy who would have become king by taking from a stone the famous magic sword called Excalibur. Using this story as a metaphor, this article has as objective to problematize innatism and apolitical conceptions of the playfulness for the teacher education. Like the idea of playfulness as a magical way to solve all the problems of the school; besides bringing notes for the use of the playful as a way to teach scientific concepts. Taking the culturalhistorical psychology as a reference, the article, as a theoretical nature, pointed out as one of its results the idea that, in oder to the playfulness contributes to the learning of scientific concepts, he must put the student in activity, so that the even mobilize their psychological processes. In order for such factors to occur, the activity needs to be designed so that the concepts occupy a prominent place during the game. Another result of the article points to a ludo-political formation by the Science teacher, so that games and other playful activities are consciously used to bring with them a more critical world view of reality, not just a reproductive view of prejudice. Finally, it advocated the importance of moving towards a more conscious and systematic use of the play in the teaching of science.
\end{abstract}

KEYWORDS: Playfulness. Teacher training. Teaching concepts. Teaching Sciences. 


\section{NOTAS}

${ }^{1}$ Esse conceito ficou conhecido no Brasil como Zona de Desenvolvimento Proximal (ZDP). A partir do texto de Prestes (2012), temos assumido o termo iminente ao invés do proximal, uma vez que o primeiro representa melhor aquilo que está em vias de acontecer no sujeito, mas só acontecerá se tiver auxílio do sujeito mais capaz. É possível encontrar outras traduções para o termo, como por exemplo, zona de desenvolvimento próximo e área de desenvolvimento iminente.

2 Essa não é a única perspectiva de ludicidade do campo de Ensino de Ciências. Entre os trabalhos da área podemos destacar: Cavalcanti; Soares, 2009; Cunha (2012); Soares (2013), tais trabalhos usam referenciais piagetianos para fundamentar suas concepções. Muitas delas divergem de aspectos aqui apresentados. Foge ao escopo desse trabalho a apresentação da crítica e o debate com essas ideias. Aprofundamos melhor essas diferenças em Messeder Neto (2016).

${ }^{3}$ Para aprofundar a discussão do fracasso escolar e o preconceito com a população pobre, sugerimos o estudo da obra de Patto (2015).

4 Sugerimos ver o documentário "O Riso dos Outros" para ver o papel político e nada inocente do riso e do humor na construção da sociedade.

\section{REFERÊNCIAS}

CAVALCANTI, E.L. D.; SOARES, M. H. F. B. O uso do jogo de roles (roleplaying game) como estratégia de discussão e avaliação do conhecimento químico. Revista Electrónica de Enseñanza de las Ciencias, v. 8, n. 1, p. 255-282, 2009.

CUNHA, M.B. Jogos no ensino de Química: considerações teóricas para sua utilização em sala de aula. Química Nova na Escola, v. 34, n. 2, p. 92-98, 2012.

DUARTE, N. Os conteúdos escolares e a ressurreição dos mortos: contribuição à teoria histórico-crítica do currículo. Campinas: Autores Associados, 2016.

FELÍCIO, C. M.; SOARES, M. H. F. B. Da Intencionalidade à Responsabilidade Lúdica: Novos Termos para Uma Reflexão Sobre o Uso de Jogos no Ensino de Química. Química Nova na Escola, v. 4, n. 3, p. 160-168, 2018

GOMES, M. A trilogia do riso: riso, transgressão e política na trilogia della vita de Pier Paolo Pasolini. 167 f. Dissertação (Mestrado em comunicação) Universidade Federal de Pernambuco, Recife, 2013.

MARTINS, L.M. O desenvolvimento do psiquismo e a educação escolar: contribuições à luz da psicologia histórico-cultural e da pedagogia históricocrítica. Campinas, São Paulo: Autores Associados, 2013.

MARTINS, L.M. Prefácio. In: MESSEDER NETO, H. S. O Lúdico no Ensino de Química na Perspectiva Histórico-Cultural: além do espetáculo, além da aparência. Curitiba: Prismas, 2016. 
MESSEDER NETO, H. S. O Lúdico no Ensino de Química na Perspectiva HistóricoCultural: além do espetáculo, além da aparência. Curitiba: Prismas, 2016.

PATTO, M. H. S. A Produção do Fracasso Escolar: histórias de submissão e rebeldia. 4. ed. São Paulo: Intermeios, 2015.

PRESTES, Z. Quando não é quase a mesma coisa: traduções de Lev Semionovitch Vigotski no Brasil. Campinas, SP: Autores Associados, 2012.

SACCOMANI, M.C.S. A criatividade na arte e na educação escolar: uma contribuição à pedagogia histórico-crítica à luz de Georg Lukács e Lev Vigotski. Campinas: Autores Associados, 2016.

SAVIANI, D. Pedagogia Histórico-Crítica: primeiras aproximações. 10. ed. Campinas: Autores Associados, 2008a.

SOARES, M.H.FB. Jogos e atividades lúdicas no ensino de química. Kelps: Goiânia, 2013.

VIGOTSKI, L. S. A construção do pensamento e da linguagem. Tradução de Paulo Bezerra. São Paulo: Martins Fontes, 2009.

Recebido: 07 mar. 2019

Aprovado: 22 set. 2019

DOI: $10.3895 /$ actio.v4n3.9764

Como citar:

MESSEDER NETO, H da S. O jogo é a Excalibur para o ensino de ciências?: apontamentos para pensar o lúdico no ensino de conceitos e na formação de professores. ACTIO, Curitiba, v. 4, n. 3, p. 77-91, set./dez.

2019. Disponível em: <https://periodicos.utfpr.edu.br/actio>. Acesso em: XXX

Correspondência:

Hélio da Silva Messeder Neto

Campus Universitário de Ondina, R. Barão de Jeremoabo, 147 - Ondina, Salvador - BA, 40170-115.

Direito autoral: Este artigo está licenciado sob os termos da Licença Creative Commons-Atribuição 4.0

Internacional.

(c) (i) 